\title{
Sutdy of A CPW-Fed Slot Dipole One-Sided Directional Antenna for UWB Systems
}

\author{
H. Kanaya, T. Hashiguchi, R. K. Pokharel, and K. Yoshida \\ Graduate School of Information Science and Electrical Engineering \\ Kyushu University \\ 744, Motooka, Fukuoka, 819-0395, JAPAN \\ kanaya@ed.kyushu-u.ac.jp
}

\begin{abstract}
This paper presents the design method of the CPW-fed slot dipole antenna for one-sided directional ultra wide band (UWB) high band application. By using and controlling the three resonances from the slot and antenna substrate, we can realize the wide band radiation. The tested antenna size is $16 \mathrm{~mm} \times 29$ mm.
\end{abstract}

Keywords-Slot antenna, ultra wide band (UWB), coplanaer waveguide.

\section{INTRODUCTION}

Ultra wide band (UWB) technology has become the most promising solution for future short-range and high-speed wireless data communication application such as home server and cable less PC system [1].

In 2002, the Federal Communication Commission (FCC) in United States officially released the regulation for UWB technology [2]. FCC regulated the emission limits for the allocated $7.5 \mathrm{GHz}$ band unlicensed use of commercial UWB communication devices. However, because interference from the $5 \mathrm{GHz}$-band wireless LAN (IEEE 802.11a) systems becomes a serious problem, this band is avoided and it provides low band $(3.4 \mathrm{GHz}-4.8 \mathrm{GHz})$ and High band (7.25 $\mathrm{GHz}-10.25 \mathrm{GHz}$ ), respectively, in Japan.

For size reduction of the UWB devices, there are many reports for planar UWB omni directional antennas, for example, planar inverted cone antenna [3], tapered-slot-fed slot antenna [4], printed circular disc monopole antenna [5], and so on. However, the characteristics of the omni directional antennas are remarkably deteriorated if metal blocks like a ground plane of monolithic microwave integrated circuits (MMIC's) or body of a car approach, because of the electro-magnetic interference. So that, UWB antenna, which has one-sided directional is necessary.

The coplanar waveguide (CPW) transmission lines have lower radiation leakage and less dispersion than microstrip lines. Also, they are preferable for MMIC and RFIC (radio frequency integrated circuit) since no via holes are required for integration with devices $[6,7]$. Slot antennas with ground plane are suitable for CPW-fed configuration and achieve onesided directional. In our previous works, we designed the CPW-fed slot dipole antenna whose length is one-wavelength with a bandpass filter using CPW lines, which acts as an impedance matching circuit as well [8-10].

In this paper, we design the slot antennas with floating metal layer on the bottom side, which have one-sided directivity for UWB high band $(7.25 \mathrm{GHz}-10.25 \mathrm{GHz})$ application. By using the three resonances appeared from the slot and substrate, we can realize the wide band radiation. We design and simulated by using the commercial electromagnetic (EM) field simulator (Ansoft; HFSS, ver.10). We also carried out experiments on the UWB antenna by using FR4 printed circuit board.

\section{ANTENNA DESIGN}

Fig. 1 shows the CPW-fed slot antenna with onewavelength center feed line. Cross section of the substrate is also shown. This antenna has a conductor-baked configuration. The substrate has dielectric constant $\varepsilon_{\mathrm{r}}=4.25$ and $\tan \delta=0.015$. The thickness of the dielectric substrate and metal $(\mathrm{Cu})$ layer, which has conductivity $=5.8 \times 10^{7} \mathrm{~S} / \mathrm{m}$, is $1.6 \mathrm{~mm}$ and $18 \mu \mathrm{m}$, respectively. Fig. 2 shows the simulated radiation patterns of the slot antenna with a floating conductor and without floating conductor, respectively. This floating conductor suppresses the radiation of the downward direction ( $Z$ direction). Figs. 3(a) and 3(b) shows the input impedance $\left(Z_{i n}=R_{i n}+j X_{i n}\right)$ and return loss of the standard slot dipole antenna. We can see the resonance of the slot antenna appears at $8.6 \mathrm{GHz}$, where input impedance matches to $50 \Omega$. However, this antenna doesn't satisfy the bandwidth of the UWB high-band. Also, we can see the parallel resonances at around $7.5 \mathrm{GHz}$ and $10.5 \mathrm{GHz}$, but they do not match to $50 \Omega$ (See point $A$ and $C$ in Fig. 3). If these resonance points can be moved and input impedance matches to $50 \Omega$, the wider bandwidth becomes possible.

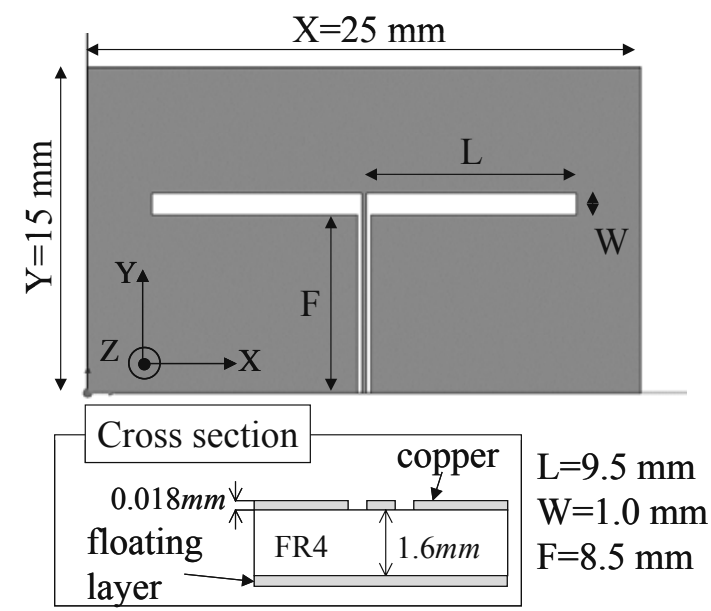

Figure 1. Layout of standard slot dipole antenna.

This work was partly supported by a Grant-in-Aid for Scientific Research (C) from the Japan Society for the Promotion of Science (JSPS). 

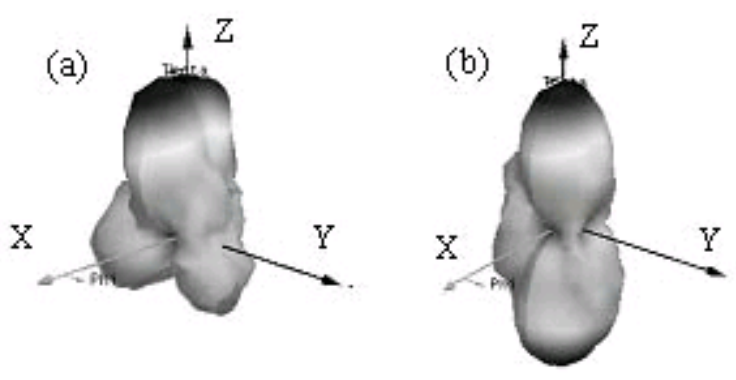

Figure 2. Simulated radiation patterns of the slot antenna with a floating conductor (a) and without a floating conductor (b).
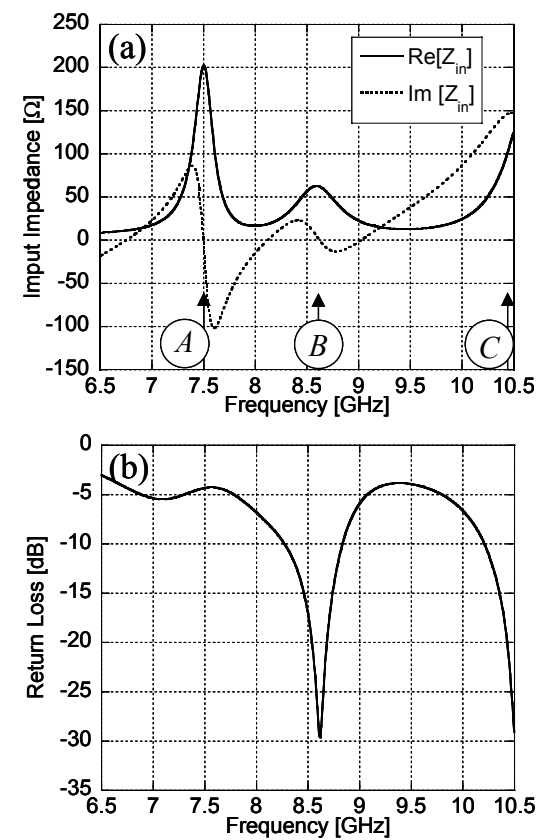

Figure 3. Input impedance (a) and return loss (b) of the standard slot dipole antenna.

Fig. 4 shows the simulated electric field distribution on the slot antenna at $7.75 \mathrm{GHz}$ (point $A$ ). This frequency moves from $7.5 \mathrm{GHz}$ to $7.75 \mathrm{GHz}$ when the value of $X$ is adjusted to $29.0 \mathrm{~mm}$. It is thought that this resonance is done by the width $(X)$ of the antenna substrate. The input impedance moves to 50 $\Omega$ at resonant frequency when the length of the square slot $(X 1)$ is adjusted to $5.0 \mathrm{~mm}$.

Fig. 5 shows the electric field distribution on the slot antenna at $9.75 \mathrm{GHz}$ (point $C$ ). This frequency moves from $10.5 \mathrm{GHz}$ to $9.75 \mathrm{GHz}$ when the value of $Y 1$ is adjusted to 7.0 $\mathrm{mm}$. It is thought that this resonant frequency is a resonance that happens between the slot of the antenna and the front edge of the substrate. The input impedance moves to $50 \Omega$ at resonant frequency when the value of $L$ is adjusted to $11.5 \mathrm{~mm}$. Also, the resonant frequency and input impedance of point $A$ hardly moves even if we adjust $Y$ and $L$.

Fig. 6 shows the electric field distribution on the slot antenna at $8.75 \mathrm{GHz}$ (point $B$ ). The frequency moves to 8.75 $\mathrm{GHz}$ when the value of $F$ is adjusted to $8.0 \mathrm{~mm}$. It is thought

that this resonance is caused by the resonance of the slot antenna with feed line. The input impedance moves to $50 \Omega$ at resonant frequency when the value of $W$ is adjusted to $1.0 \mathrm{~mm}$. Also, the frequency of point $A$ and $C$ hardly moves even if we executed the above process.

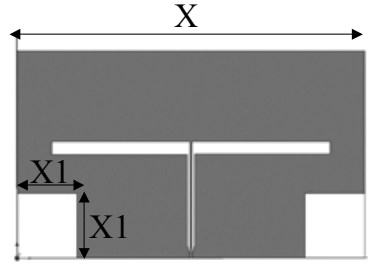

Layout

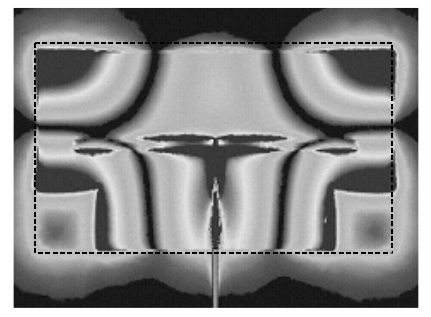

Figure 4. Simulated electric field distribution on the UWB slot antenna at $7.75 \mathrm{GHz}$.

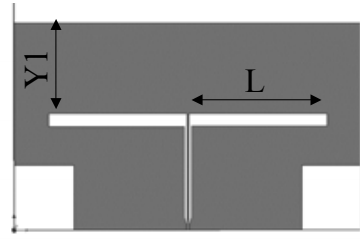

Layout

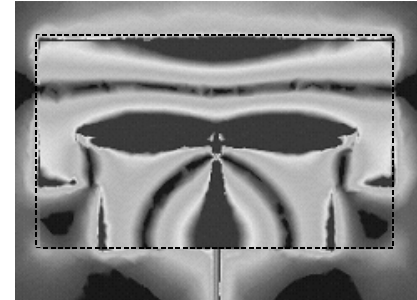

Figure 5. Simulated electric field distribution on the UWB slot antenna at $9.75 \mathrm{GHz}$.

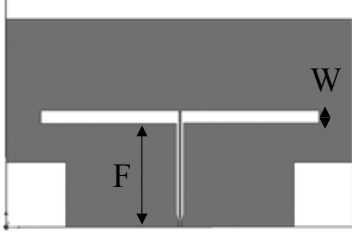

Layout

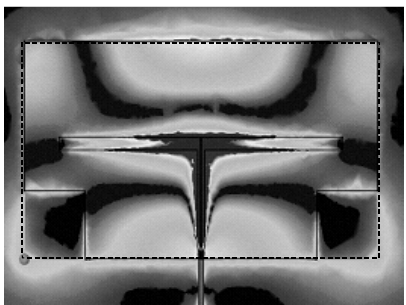

Figure 6. Simulated electric field distribution on the UWB slot antenna at $8.75 \mathrm{GHz}$.

\section{ANTENNA CHARACTERISTICS}

Figs. 7(a) and 7(b) show the simulated input impedance and return loss of the UWB antenna, where $\operatorname{Re}\left[Z_{i n}\right]$ represents radiation resistance and transmission loss, and $\operatorname{Im}\left[Z_{i n}\right]$ is the reactance of the antenna. The input impedance is almost $50 \Omega$, and $-10 \mathrm{~dB}$ bandwidth is almost satisfying the UWB high band. Fig. 8 shows the simulated frequency dependence of the $\phi=0^{\circ}$ and $\phi=90^{\circ}$ element of the electric field $E_{\phi}$ (See the direction in Fig. 8). In each frequency, because the value of $E_{\phi=0^{\circ}}$ is larger than that of $E_{\phi=90^{\circ}}$, it can be said that the polarization of the electric field is almost the same in the UWB high band. 
Fig. 9 shows the radiation pattern of the UWB slot antenna at different frequencies. The directivity for upward direction is larger than that of lower direction. Fig. 10 shows the frequency dependence of the peak gain at $\theta=0$ (upward) and peak realized gain, respectively. The radiation efficiency is $70 \%$ or more in the UWB high band because of the conductor and dielectric loss. We can see that this UWB antenna has a peak realized gain more than $5 \mathrm{~dB}$ in UWB high band.
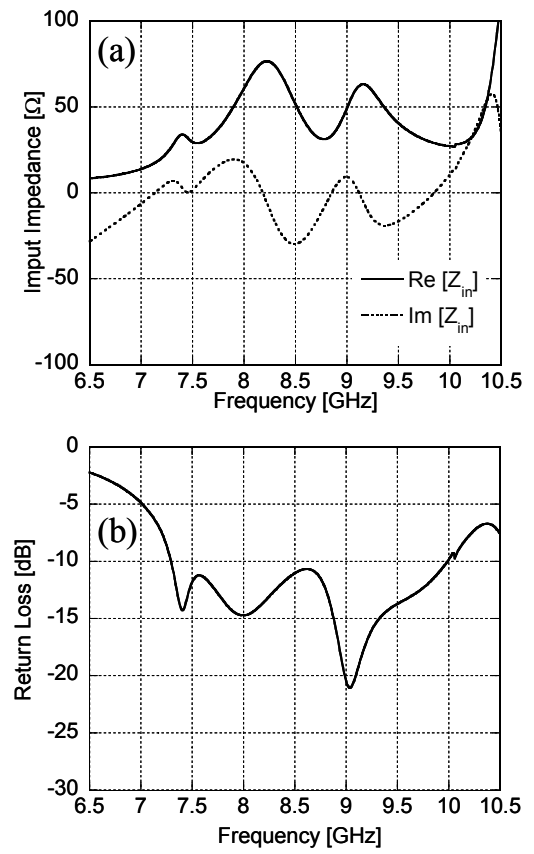

Figure 7. Input impedance (a) and return loss (b) of the UWB slot dipole antenna.

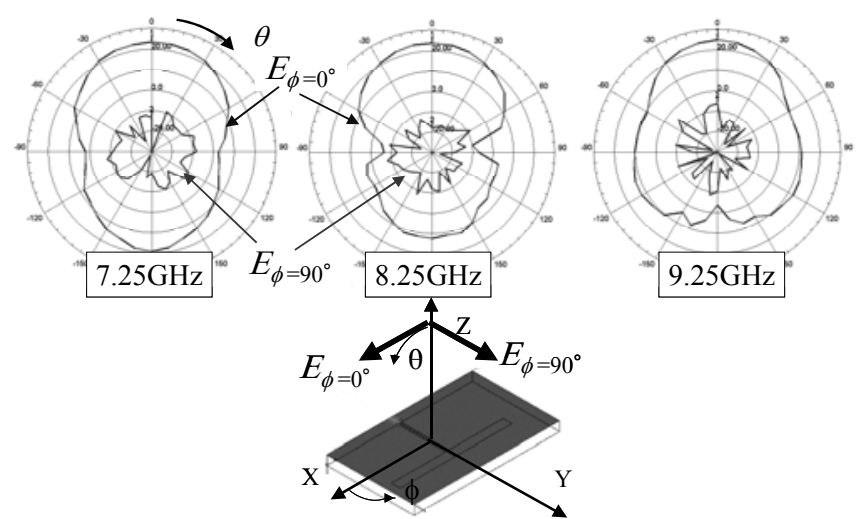

Figure 8. Frequency dependence of the $\phi=0^{\circ}$ and $\phi=90^{\circ}$ element of the electric field $E_{\phi}$.

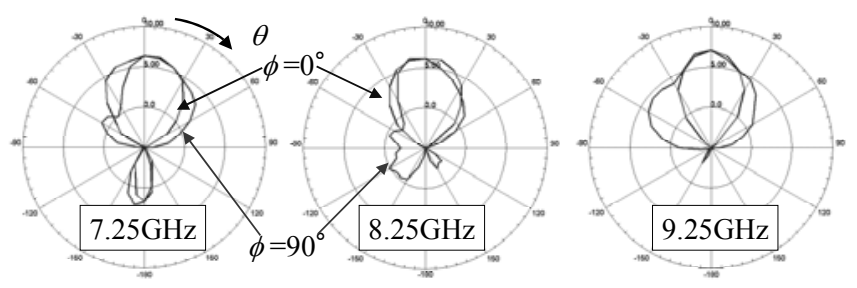

Figure 9. Simulated radiation pattern of the UWB slot dipole antenna with ground plane.

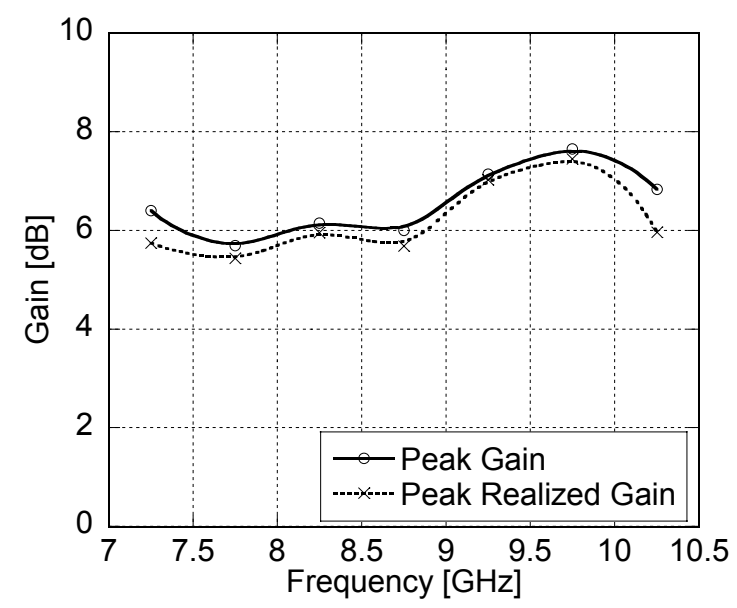

Figure 10. Frequency dependence of the upward peak directivity and peak realized gain.

\section{EXPERIMENTAL RESULTS AND DISCUSSIONS}

An UWB antenna is fabricated on FR4 substrate by using the print board making equipment (MITS; FP-21T model 40), which has $100 \mathrm{~mm}$-diameter milling cutter. Fig. 11 shows the photographs of the antenna fabrication system, and the UWB fabricated antenna, respectively. In the figure, the close up of the high-frequency milling cutter is also shown. We measured the $S$-parameters by using a GP-IB controlled vector network analyzer (HP; HP8722C) through MMCX connector which has characteristic impedance $=50 \Omega$.

\section{Prirted board making equipment}

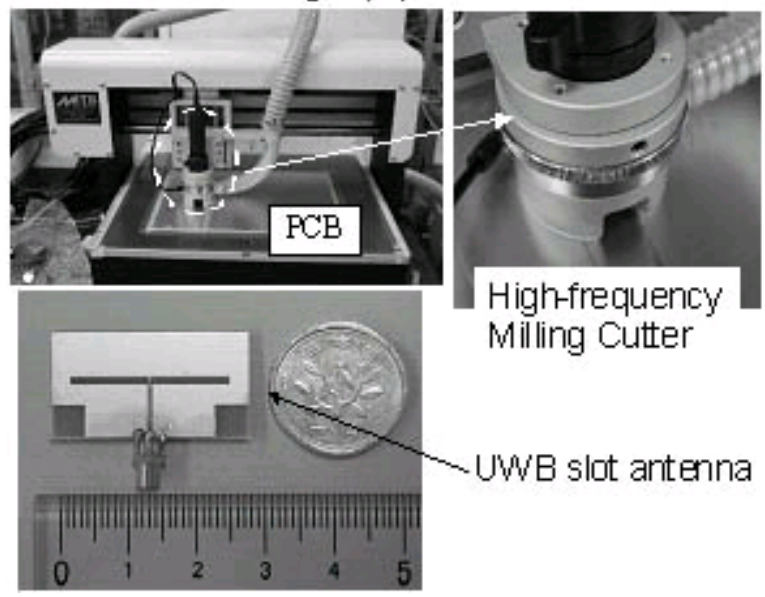

Figure 11. Photographs of the antenna fabrication system and UWB slot antenna.

Fig. 12 and Fig. 13 show the experimental results of the input impedance and return loss of the one-sided directional UWB antenna, respectively. In Fig. 13, broken line shows the return loss of the EM simulated result. It seems that the bandwidth slightly decreases, however, three-designed frequencies appear and match to almost $50 \Omega$. Also, the real part of input impedance is larger in low frequency region than that of EM simulated results (see Fig. 7). The observed 
experimental results are caused by an error in edge part of the slot antenna for milling process, an error of the dielectric constant of the FR4 substrate and residual loss of the connection between the MMCX connector and antenna. However, this design method and the experimental results may be comparatively corresponding.

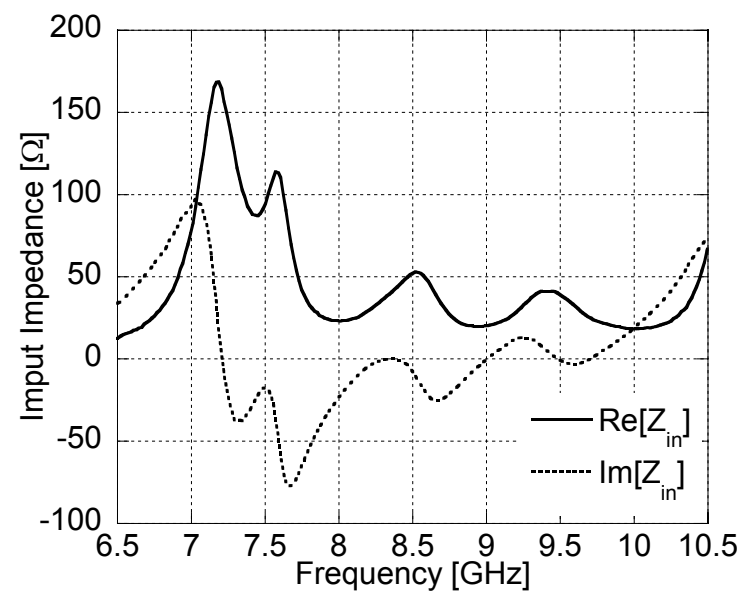

Figure 12. Measured input impedance of the UWB slot antenna.

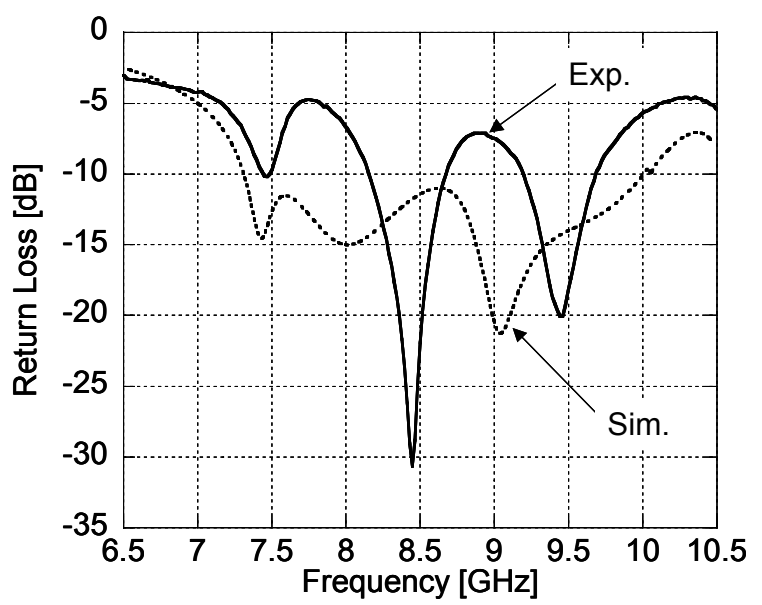

Figure 13. Measured return loss of the UWB slot antenna.

\section{CONCLUSIONS}

We studied the design method of the CPW-fed slot dipole antenna with one-sided directional for ultra wide band (UWB) high band application. For realize the one-sided directional, we applied the floating metal layer on the bottom of the antenna substrate. By using and controlling the three resonances from the slot and substrate, we can realize the wide band radiation and impedance matching. The commercial three-dimensional EM simulator simulates RF characteristics. Moreover, this UWB antenna was fabricated and tested, thereby we demonstrated frequency characteristics as expected. The tested antenna size is $16 \mathrm{~mm} \times 29 \mathrm{~mm}$.

Now, we measure the communication distance of the UWB test signal by implementing this antenna into commercial system, and this antenna is shown to transmit the UWB pulse. This result will be published elsewhere.

\section{REFERENCES}

[1] Z. N. Chen, X. H. Wu, H. F. Li, N. Yang, and Y. W. Chia, "Consideration for Source Pulses and Antennas in UWB Ratio System," IEEE Trans. Antennas Propagat., vol. 52, no. 7, pp. 1739-1748, July 2004.

[2] "First Report and Order, Revision of Part 15 of the Commission's Rule Regarding Ultra Wideband Transmission Systems," Fed. Commun. Comm., FCC 02-48, April 2002.

[3] S. Y. Suh, W. K. Stutzman, and W. A. Davis, "A New Ultrawideband Printed Monopole Antenna: The Planar Inverted Cone Antenna (PICA)," IEEE Trans. Antennas Propagat., vol. 52, no. 5, pp. 1361-1365, May 2004.

[4] T. G. Ma, and S. K. Jeng, "Planar Miniature Tapered-Slot-Fed Annular Slot Antennas for Ultrawide-Band Radios," IEEE Trans. Antennas Propagat., vol. 53, no. 3, pp. 1194-1202, March 2005.

[5] J. Liang, C. C. Chiau, X. Chen, and C. G. Parini, "Study of a Printed Circular Disc Monopole Antenna for UWB Systems," IEEE Trans. Antennas Propagat., vol. 53, no. 11, pp. 3500-3504, November 2005.

[6] B.K. Kormanyos, W. Harokopus, L. Katehi, and G. Rebeiz, "CPW-fed active slot antennas", IEEE Trans. Microwave Theory \& Thech., vol. 42, pp.541-545, April, 1994.

[7] S. S. Garcia, and J. J. Laurin, " Study of a CPW Inductively coupled slot antenna", IEEE Trans. Antennas Propagat., vol. 47, no. 1, pp. 58-64, January 1999.

[8] K. Yoshida, T. Takahashi, H. Kanaya, T. Uchiyama, and Z. Wang, "Superconducting slot antenna with broadband impedance matching circuit," IEEE Trans. Appl. Supercond., vol. 11, pp. 103-106, March 2001.

[9] H. Kanaya, Y. Koga, G. Urakawa, and K. Yoshida, "Design of HTS Coplanar Waveguide Matching Circuit for Low Noise CMOS-HTS Receiver," IEEE Trans. on Appl. Supercond., vol. 13, no. 2, pp. 10311034, June 2003.

[10] K. Yoshida, Y. Tsutsumi, and H. Kanaya "Electrically Small Antennas with Miniaturized Impedance Matching Circuits for Semiconductor Amplifiers," IEICE Trans. Electron., vol. E88-C, pp1368-1374, no. 7, July 2005. 